\title{
Pierre Ostiguy, Francisco Panizza \& Benjamin Moffitt (eds). Populism in Global Perspective. A Performative and Discursive Approach. New York: Routledge, 2021.
}

\author{
Claudio Riveros (iD \\ Universidad de Talca, Chile. \\ clriveros@talca.cl
}

Populism in Global Perspective. A Performative and Discoursive Approach es un libro que propone entender al populismo desde una perspectiva relacional, performativa y lógico discursiva con el objeto, en primer lugar, de superar un enfoque analítico que comprende al fenómeno como una estrategia política en el que un líder apela vertical y emocionalmente a seguidores desorganizados, con pocos recursos y bajos niveles de educación (Weyland, 2017). En segundo lugar, los autores también desafían al enfoque ideacional, propuesta teórica que entiende al populismo como una ideología delgada en la que la sociedad se separa en dos grupos homogéneos y antagónicos: el "pueblo puro" y la "elite corrupta", y en donde la política debe ser siempre el resultado de la voluntad general (Mudde \& Rovira, 2017). Los autores deslizan tres críticas a este enfoque, hoy por hoy dominante: primero, plantean que es difícil sostener que el populismo pueda catalogarse como una ideología; segundo, que definir a la élite como corrupta o al pueblo como moralmente bueno se explican en un contexto, principalmente europeo y no le son propias a todas las configuraciones populistas; y tercero, que la apelación discursiva a la voluntad general no es algo intrínseco al populismo si no que obedece a un horizonte democrático.

En efecto, los editores del libro plantean un enfoque original en tanto combina, por una parte, lo preconizado por el enfoque lógico-discursivo (Laclau, 2005), y por otra, el enfoque socio-cultural/performativo. Y es en esta combinación de propuestas donde se visualiza el aporte, pero también, la tensión del escrito. Es un aporte, en tanto viene a "superar" una concepción del populismo que se basa, principalmente, en su capacidad articulativa, formal, otorgándole un contenido socio-cultural pero también político. Se apunta, entonces, a entender cómo opera el significante pueblo, las prácticas identitarias entre el líder y sus seguidores, y principalmente, a identificar cuáles son los elementos culturales y sociales que dan forma a una construcción que se quiere hacer hegemónica. Es en estos aspectos, donde el "contenido" cuenta y mucho. Con todo, la tensión está presente en la medida que lo performativo puede ser entendido como una performance o como el acto de creación de la cadena equivalencial, que superaría la construcción del discurso populista. Es decir, si el populismo va más allá de una construcción de un discurso y se percibe antes bien como una relación socio-cultural entre el líder y sus seguidores, sea entendido como el resultado de luchas hegemónicas, del alarde de lo bajo o la particular relación y su expresión en repertorios performativos (tipo de palabras y emociones desplegadas), no queda del todo claro si el rasgo fundamental para entender si se está en presencia 
Pierre Ostiguy, Francisco Panizza \& Benjamin Moffitt (eds). Populism in Global Perspective. A Performative and Discursive Approach. New York: Routledge, 2021, 308 páginas.

del populismo es lo discursivo, lo performativo, o debe incluir la presencia de ambas dimensiones, aun cuando los autores así lo propongan. Así, por ejemplo, en una cultura política en la que hay una notoria ausencia del alarde de lo bajo, como en el caso chileno, ¿pueden configurarse articulaciones populistas? Mi impresión es que sí. Entonces, desde una perspectiva relacional y cultural lo fundamental, en ese caso particular, sería concentrarse en la construcción de las identidades políticas y no tanto así en la performance, en tanto relación corporal o gestual del líder con sus seguidores. Pero también podría darse la posibilidad de que se construya una performance típicamente populista, pero que el discurso solo se elabore con fines políticos como una simple estrategia retórica para llegar al poder. ¿Qué pasa en esos casos? Cuestión no menor, precisamente en una propuesta analítica que intenta superar dicha concepción y en la que se espera comprender al populismo como una relación vertical-horizontal entre el líder y sus seguidores, producto de una interacción interpelativa. Por último, e incluso dilucidando lo anterior, considero que sería necesario responder en futuras investigaciones si la apuesta está en sacrificar (o cómo evitarlo) performatividad por performance, pese a que los autores intenten conciliarlas. Esto constituye un problema ineludible, puesto que conceptualizar al populismo como un estilo donde predominan las "bad manners" o el alarde de lo bajo sin mayor anclaje social e institucional, por parte de algunos estudiosos, podría acercarlo a nociones caricaturescas en el que se entiende al fenómeno como un simple teatro mediático, una parodia de representación democrática.

Con todo, habría que subrayar que el texto no se limita a entender al populismo desde la figura de un líder, pese a que se reconoce su importancia, pues también incorpora a los partidos políticos y se detiene a analizar el rol que cumplen los movimientos sociales como, incluso, desencadenantes del fenómeno. Así también, no es menos destacable que los editores mantengan cierto recelo a un análisis que se focalice esencialmente en el discurso de los líderes y/o a la predisposición del votante a tener actitudes populistas; entendido como un juego de oferta y demanda. En realidad, como sostienen los autores, "el populismo es una apelación afectiva y performativa que es efectiva en determinados contextos" (8). De hecho, una de las principales conclusiones que se puede extraer del texto es que no basta con identificar la existencia de un discurso populista, cuestión a que no pocas veces se ha limitado la teoría ideacional, sino que fundamentalmente a indagar el por qué la presencia de dicho discurso y entender cómo se constituye y construye la cadena equivalencial desde una perspectiva performativa.

El texto se compone de una Introducción, Conclusión y once Capítulos: dos de ellos teóricos, estos últimos elaborados por los editores del texto y los restantes nueve capítulos donde se aplican con mayor o menor intensidad a nivel empírico y utilizando una metodología inductiva los postulados esbozados en los capítulos teóricos, aunque habría que decir que algunos de estos capítulos constituyen también un aporte teórico en sí mismo. Destaca sobre manera dos cosas: en primer lugar, el hecho de que los capítulos no solo sigan la línea teórica propuesta, sino que entre ellos se establezca un permanente diálogo que es posible observar mediante referencias cruzadas. En segundo lugar, también es destacable que el campo de estudio se amplíe a contextos como América Latina, E.E.U.U., Turquía, Filipinas o Sudáfrica.

Ahora bien, sin que pueda extenderme en el análisis de cada uno de los capítulos, me gustaría destacar algunas herramientas teóricas que pueden ser utilizadas y profundizadas por distintos estudios en el futuro:

En primer lugar, la noción de que la articulación populista no toma lugar en un vacío político, sino que, por el contrario, destaca como expresión de una lógica polarizadora, antagonista, que toma forma tanto de un líder o movimiento populista, así como también a través de discursos o incluso desde una institucionalidad antipopulista, arguye Grigoris Markou. Tal como argumentan Panizza y Stavrakakis, 
el populismo no es per se un peligro a la democracia, sino por el contrario, es un discurso político que es inherente al discurso democrático, pero que puede tomar diferentes rumbos (si se quiere, derecha o izquierda, autoritaria o no) en atención a representar el descontento social por una población que no se ve auténticamente representada por los actores políticos establecidos.

En segundo lugar, como destacan Ostiguy y Moffitt, el populismo se puede caracterizar como un particular estilo performativo en el que, contrario al planteamiento de Laclau, el significante que aglutina no es vacío, sino que desborda de significaciones. Para ellos, es precisamente el "significante desbordante" el que posibilita el esfuerzo de una construcción hegemónica y eso teóricamente es un aporte valiosísimo que supera a la ortodoxia laclauniana y constata la dimensión sociológica del escrito.

Atendiendo entonces a una relación sinérgica que se construye entre líder y seguidores, propugnan un populismo que se ancla en lo socio-cultural, pero que se expresa de una manera particular, en tanto expresión de lo bajo y de los malos modales. Continuadora de esta línea, María Esperanza Casullo, argumenta que el populismo es una forma particular de representación, que denomina "synecdochal" y en la que el líder/lideresa asume una identidad popular sin perder la propia, desde lo concreto, desde lo físico. Así, analizando el impacto del cuerpo en la política, determina que sus vías de expresión van desde la ropa que usa, sus modales y su nivel educativo. Tiene un valor en sí mismo el hecho el estudio del cuerpo como medio de representación, sin embargo, si el populismo obedece principalmente a una performance corpórea no queda claro en qué medida es importante el discurso y si lo fuera, cómo se determinarían dichos grados. Esta tensión también aparece en el texto de Sithembile Mbete, aunque en menor medida en el artículo de Nicole Curato, quienes indagan en el caso sudafricano y filipino respectivamente. En definitiva, cierto es que se podría argumentar que el cuerpo es también una expresión discursiva, performativa, pero es en este punto donde continúa la tensión, o antes bien, una separación teórica del reseñador con algunos de los autores. Ello, pues si identifico un discurso populista (desde la teoría ideacional o laclauniana) existe ya populismo, entonces, la performance pasa a ser un añadido; en otras palabras, la "transgresión populista" me sería indiferente para concluir que se está bajo su presencia; pero, por el contrario, si aquí lo que se argumenta es que el discurso en tanto construcción de cadenas, significantes, oposición pueblo-bloque de poder, entre otras, debe ir acompañado de una performance populista; de nuevo, ¿qué ocurre en un país en la que esa transgresión no está incorporada culturalmente al modo de hacer política? ¿nunca podrá ser populista o lo será en menor grado?

En tercer lugar, en el texto se discute respecto a cómo opera el populismo como proyecto y régimen político. En estos aspectos destaca el artículo de Samuele Mazzolini, quien en su estudio del proceso populista llevado a cabo por Rafel Correa en Ecuador desafía, por una parte, la noción de que el populismo se opone a toda institucionalidad; y por otra, cuestiona la idea de entender al populismo únicamente desde una lógica formal discursiva que carece de un proyecto político (Mouffe, 2018), pues ello no permitiría entender cómo éste se trasunta hegemónicamente en el poder. El autor, entonces, pareciera entender al populismo como un proceso que se construye hegemónicamente mediante una articulación discursiva en tanto proyecto político que desafía al bloque de poder, pero que una vez en el gobierno, necesita recrear el antagonismo hasta un punto en el que las distintas demandas no sean superadas por el líder, quien se transforma en el eje de los significantes, sea como significante vacío o como articulador del significante flotante. En esta "guerra" de posiciones, en esta batalla cultural de sentidos comunes es donde se jugaría el éxito o el fracaso de un régimen. Esto explicaría lo acontecido con Correa en Ecuador y muy probablemente el caso de Syriza (2015-2019) en Grecia, que analiza Grigoris Markou. 
En cuarto lugar, los capítulos que estudian el caso de Estados Unidos, en específico el fenómeno de Trump y Sanders, así como lo acontecido con Erdogan en Turquía, más allá de su pertinencia contemporánea, permiten atisbar contextos políticos que parecieran ser propensos al desarrollo de líderes, movimientos y partidos populistas, sean de izquierda y derecha, producto de un discurso populista siempre disponible y que respondería a una especie de clivaje cultural dentro de la sociedad, o incluso, como un eje de identificación. De ser efectiva esta interpretación, éste sería un verdadero hallazgo teórico y permitiría ampliar lo que en Argentina se ha denominado la grieta. En quinto y último lugar, el capítulo de De Cleen, Glynos y Mondon, indaga en los denominados populismos de derecha que constantemente se estarían desarrollando en Europa occidental. Los autores, desafiando los análisis predominantes sobre la materia, postulan que metodológica y teóricamente se debe distinguir entre una lógica populista y los diferentes proyectos políticos que se despliegan junto a ésta. Ello en un contexto académico en el que los populismos de derecha radical son identificados con ideologías nativistas y xenófobas. Según los autores, si bien los populismos pueden desplegar tales elementos el fenómeno se produce de modo inverso; esto es, son ideologías nativistas las que, mediante partidos y líderes, utilizan una estrategia populista para llegar de forma más directa y cercana a la población. Y no solo eso, serían los mismos medios de comunicación y académicos quienes paradójicamente matizarían dichas ideologías al enjuiciarlas como populistas y no propiamente por lo que son: nacionalismos excluyentes, nativistas y xenófobos. Con todo, llama la atención de que los autores prefieran seguir denominando a dichos partidos como populistas, pese a la crítica conceptual deslizada.

En definitiva, el texto Populism in Global Perspective. A Performative and Discoursive Approach, constituye, sin duda, un aporte sobre la materia e invita a reflexionar desde un enfoque que combina armónicamente la propuesta lacluneana desde una perspectiva performativa y en la que la articulación discursiva debe ser vista como una parte de lo que podríamos denominar un proceso populista. Proceso que, pese a lo propuesto por Laclau en su texto original, posee una institucionalidad propia y que tiene un anclaje cultural que intenta expresarse hegemónicamente. Es, sin duda, un libro que debe ser leído.

\section{REFERENCIAS}

Laclau, E. (2005). La Razón Populista. Buenos Aires: Fondo de Cultura Económica.

Mouffe, C. (2018). For a left Populism. New York: Verso.

Mudde, C., \& Rovira, C. (2017). Populism. A very short Introduction. Oxford: Oxford University Press

Weyland, K. (2017). Populism. A Political-Strategic Approach. En C. Rovira, P. Taggart, P. Ochoa, \& P. Ostiguy, The Oxford Handbook of Populism (pp. 48-72). Oxford: Oxford University Press.

\section{NOTA BIOGRÁFICA}

Claudio Riveros es profesor conferenciante de la Escuela de Ciencias Políticas y Administración Pública de Facultad de Ciencias Sociales de la Universidad de Talca (Chile). Es Investigador Postdoctoral y autor del libro El Proceso Populista. Momento, fenómeno, régimen: Chile el caso que no fue (1932-1973), 2018, Raleigh, E.E.U.U.: A Contracorriente (UNC Press). 